\title{
Percepção de usuários sobre educação ambiental nas estratégias de saúde da família de Cáceres/MT
}

As cidades sofrem constantes transformações em seu contexto urbano e lidam com processos de adaptação frente a cenários econômicos, políticos e ambientais O estudo objetivou identificar a percepção dos usuários de saúde, considerando a saúde e meio ambiente: educação ambiental nas Estratégias de Saúde da Família (ESFs) de Cáceres-MT. Foram realizadas entrevistas semiestruturada com 120 usuários que se dispuseram em participar da pesquisa. As etapas foram constituídas por levantamento bibliográfico, coleta e análise de dados. E, preconizadas as técnicas de análise do conteúdo de Laurence Bardin para análise qualitativa. Foram realizadas associações pelo Teste Qui quadrado com correção de Bonferroni e uso do teste Exato de Fisher quando identificada associação significativa entre as seis localidades, por meio do programa Bioestat 5.0, considerando um nível de significância de $5 \%$ para os dados quantitativos. Os resultados revelaram que a maioria dos usuários não compreende os aspectos de saúde e ambiente e EA de forma sistêmica na realidade das Estratégias de Saúde da família de Cáceres, mesmo havendo destaque para os diversos aspectos ambientais que influenciam sobre a saúde humana. As intervenções educativas nas ESFs seguem metodologias simples tradicionais centradas na transmissão de conhecimentos pontuais com ênfase nas doenças sem visão abrangente e ação integral sobre os problemas ambientais que afetam as comunidades, dificultando o desenvolvimento de ações que abarquem a promoção da qualidade de vida da população e, portanto, o desenvolvimento sustentável nos âmbitos social, econômico e ambiental.

\section{Perception of users on environmental education in the health strategies of the family of Cáceres/MT}

Cities undergo constant changes in their urban context and deal with adaptation processes in the face of economic, political and environmental scenarios. The study aimed to identify the perception of health users, considering health and the environment: environmental education in the Family Health Strategies (ESFs) of Cáceres-MT. Semi-structured interviews were conducted with 120 users who were willing to participate in the research. The stages consisted of a bibliographic survey, data collection and analysis. And, the techniques of analysis of the content of Laurence Bardin are recommended for qualitative analysis. Associations were made using the Chi-square test with Bonferroni correction and use of Fisher's exact test when a significant association was identified between the six locations, using the Bioestat 5.0 program, considering a $5 \%$ significance level for quantitative data. The results revealed that the majority of users do not understand the aspects of health and environment and AE in a systemic way in the reality of the Health Strategies of the Cáceres family, even though there are prominence for the various environmental aspects that influence human health. Educational interventions in ESFs follow simple traditional methodologies centered on the transmission of specific knowledge with an emphasis on diseases without a comprehensive view and comprehensive action on environmental problems that affect communities, making it difficult to develop actions that encompass the promotion of the population's quality of life and therefore, sustainable development in the social, economic and environmental spheres.

Keywords: Environmental perception; Environmental education; Health and environment; Family health strategy.

Topic: Educação Ambiental

Reviewed anonymously in the process of blind peer
Received: 03/04/2021

Approved: 26/04/2021
Eva Couto Garcia (iD)

Universidade do Estado de Mato Grosso, Brasil

http://lattes.cnpq.br/9491254969229489

http://orcid.org/0000-0003-2629-8354

evacougar@hotmail.com

Josué Ribeiro de Silva Nunes (iD)

Universidade do Estado de Mato Grosso, Brasil

http://lattes.cnpq.br/3292016056510295

http://orcid.org/0000-0003-3927-5063

josue@unemat.br
Referencing this:

GARCIA, E. C.; NUNES, J. R. S.. Percepção de usuários sobre educação ambiental nas estratégias de saúde da família de Cáceres/MT. Revista Ibero Americana de Ciências Ambientais, v.12, n.4, p.767-782, 2021. DOI: $\underline{\text { http://doi.org/10.6008/CBPC2179-6858.2021.004.0058 }}$ 


\section{INTRODUÇÃO}

A relação do homem com o meio ambiente representa uma das questões frequentemente discutida na sociedade em diferentes lugares do planeta. Diversas modificações causadas por ações antrópicas contabilizam uma série de repercussões no âmbito sócio-econômico-ambiental gerando graves problemas de saúde pública (MORAES et al., 2014).

A problemática da degradação ambiental tem atingido todo ecossistema a nível mundial, não se limitando a fronteiras geográficas tornando-se um desafio considerado global para todos os habitantes do planeta. Nós, que somos parte integrante deste contexto, estamos contribuindo para a propagação de várias alterações ambientais que ameaçam inclusive a nossa sobrevivência.

Com destaque para a degradação dos sistemas vitais, mudanças climáticas, diminuição da biodiversidade, erosão do solo, secas e inundações. Trata-se do ambiente onde estamos inseridos onde ocorrem as interações e inter-relações que influenciam de forma direta e indireta do processo de saúdedoença da população.

Carvalho et al. (2009) pontuam que a educação ambiental tem sido discutida como possibilidade de minimizar os problemas decorrentes das alterações ambientais, vem se destacando como uma prática que poderia gerar movimentos de transformação entorno da prevenção dos riscos e da degradação ambiental.

$\mathrm{Na}$ atuação prática dos profissionais observa-se que a educação ambiental e educação em saúde poderiam fazer parte de um processo complementar de aprendizagem, visto que ambas se destinam a promoção de qualidade de vida das pessoas. Pois o processo saúde-doença está diretamente relacionado com as respostas ambientais (PERES et al., 2015).

No cenário brasileiro se destacam as Estratégia de Saúde da Família (ESF) que tem por objetivo reorganizar a prática assistencial, substituindo o modelo tradicional baseado na hospitalização por uma abordagem integral com ações de promoção e prevenção de doenças através de vínculo de corresponsabilidade entre equipes e comunidades (BRASIL, 2007; BRASIL, 2012).

Compreendendo que a resposta de saúde do indivíduo está condicionada a forma de inserção na sociedade, nível cultural, condições socioeconômicas e capacidade cognitiva, o estudo buscou identificar a percepção de usuários considerando a educação ambiental como uma proposta de atuação no âmbito das Estratégias de saúde da Família do município de Cáceres-MT.

\section{REVISÃO TEÓRICA}

\section{Educação Ambiental: Contexto Histórico}

A educação ambiental (EA) surgiu como "estratégias" da sociedade para fazer frente aos problemas ambientais entendidos, como ameaças a qualidade e à vida no Planeta (UNESCO, 1994). Politicamente foi um processo resultante de movimentos sociais organizados em nível mundial, dentre os quais se destacaram o movimento Hippie, a luta dos negros americanos pela cidadania, as lutas das mulheres pela igualdade de direitos com os homens, entre outros movimentos de defesa da ecologia e do meio ambiente, cujo marco foi 
a publicação do livro "Primavera Silenciosa" (1962), da americana Raquel Carson (LE PRESTRE, 2000).

Cabendo destacar as contribuições das Conferência das Nações Unidas sobre o ambiente humano em Estocolmo 1972, Conferência Intergovernamental de Educação Ambiental de Tbilisi na Geórgia 1977, através de uma parceria entre a Organização das Nações Unidas para a Educação, a Ciência e a Cultura (UNESCO) e o Programa das Nações Unidas para o Meio Ambiente (PNUMA) (UNESCO, 1994).

Onde formularam-se objetivos, definições, princípios e estratégias para a educação ambiental, com recursos instrucionais para a implementação do método em diversos países os quais deveriam ser adotados em todo o mundo em nível de educação formal quanto informal, envolvendo pessoas de todas as idades (DÍAZ, 1995; DIAS, 2000; MORADILIO et al., 2003).

Possibilitando a aquisição de novos conhecimentos, mudanças de conduta e orientações para a preservação e resolução dos problemas do meio ambiente, através de uma metodologia interdisciplinar que compreendesse o meio ambiente considerando as questões globais em sua totalidade (DÍAZ, 1995).

No Brasil em função das Conferências e movimentos ambientalistas de opinião pública foram sinalizadas as primeiras diretrizes e estratégias a fim de estabelecer um gerenciamento ambiental, em favor da soberania e segurança nacional criando em 1973 a Secretaria Especial do Meio Ambiente (SEMA) (LIMA, 2011; SORRENTINO et al., 2005).

Constituindo de forma gradual de um sistema governamental de agências ambientais possibilitando a criação do Instituto Brasileiro do Meio Ambiente e dos Recursos Naturais Renováveis (IBAMA), em 1989; do Ministério do Meio Ambiente, em 1993; da Agência Nacional de Águas (ANA), em 2001, e do Instituto Chico Mendes de Conservação da Biodiversidade (ICMBio), em 2007, entre tantas outras iniciativas estruturadoras do setor público ambiental (LIMA, 2011).

Mas juridicamente o controle ambiental no país deu se com a Política Nacional de Meio Ambiente (PNMA) através da Lei no 6938/81, validando um avanço na legislação ambiental a partir da criação do Sistema Nacional de Meio Ambiente (SISNAMA) e do Conselho Nacional de Meio Ambiente (CONAMA) (BROMBERGER, 2003; LIMA, 2011). Já a Política Nacional de Educação Ambiental (PNEA) conhecida como a Lei da Educação Ambiental foi regulamentada através da Lei 9.597/99 sendo definida como:

Processos por meio dos quais o indivíduo e a coletividade constroem valores sociais, conhecimentos, habilidades, atitudes e competências voltadas para a conservação do meio ambiente, bem de uso comum do povo, essencial a sadia qualidade de vida e sua sustentabilidade.

Constituindo um direito de todos os cidadãos, devendo estar presente em todas as modalidades do processo educativo sendo de responsabilidade do Poder Público a definição de políticas públicas voltadas para a educação ambiental além de promover o engajamento da sociedade na conservação e recuperação e melhoria do meio ambiente.

Devendo haver uma responsabilidade compartilhada na adoção de atitudes que equilibrassem as relações do homem com o seu entorno ambiental (BURSZTYN et al., 2012). Necessitando de políticas setoriais com ações orientadas para o equilíbrio entre os sistemas ambiental, econômico e político-social (FIORINO, 2010; WU et al., 2014). 
Conforme esse ponto de vista a educação ambiental constituía responsabilidade do poder público consolidado pelo Art.225 da Constituição Federal (CF) de 1988 com intuito de sensibilizar as pessoas para a necessidade de um meio ambiente equilibrado e saudável para todos, sendo determinado que:

Todos têm direito ao meio ambiente ecologicamente equilibrado, que é um bem de uso comum do povo e essencial à sadia qualidade de vida, impondo se ao Poder Público e à coletividade o dever de defendê-lo, preservá-lo para as presentes e futuras gerações.

Cabendo ressaltar a criação do Programa de Educação Ambiental (PRONEA) que caracterizou um dos avanços mais significativos na institucionalização da educação ambiental no país visando a construção de instrumentos e metodologias para capacitação de gestores e educadores para um processo de gestão ambiental conforme proposto na CF 1988 (BRASIL, 2004).

Tornando se incontestável a importância da educação ambiental, desde cedo, na vida e na rotina do indivíduo, como forma de valorizar e respeitar o meio ambiente, pois assim será possível garantir às gerações atuais e futuras, através da adoção de medidas de precaução em relação a ações que possam vir a causar desequilíbrio do meio ambiente e risco à vida humana.

Lima (2011) enfatiza que apesar das políticas institucionais da educação ambiental avançarem relativamente no Brasil nos últimos anos. Esse cenário foi marcado por divergências e interesses contraditórios entre os países ricos e pobres ficando claro a falta de compromisso por parte de alguns países que não assumiram as responsabilidades quanto aos recursos financeiros para viabilizar o desenvolvimento sustentável proposto nas conferências internacionais (RAMOS, 2001).

A evolução desse processo deu-se de um modo contraditório, impreciso não sendo suficiente para superar a crescente degradação ambiental e conflitos políticos e econômicos decorrentes da expansão capitalista no país.

\section{Educação ambiental como ferramenta para solução dos problemas socioambientais}

No Brasil, as Diretrizes Nacionais para essa proposta apontam para a construção de um conhecimento alicerçado no desenvolvimento de habilidades, atitudes e valores sociais, cuidado com a comunidade, justiça, equidade socioambiental e proteção do meio ambiente (BRASIL, 2012).

Constituindo uma ferramenta para o enfrentamento das crises sociais partindo de uma lógica racional, transdisciplinar, vinculada a um processo educativo pautado nos valores éticos evidenciando seu caráter de responsabilidade com as questões ambientais (FONTES et al., 2017).

Dentro das políticas públicas a EA, foi defendida por Sorrentino et al. (2005) como "[...] um conjunto de procedimentos formais e informais que expressam a relação de poder que se destina à resolução pacífica de conflitos, assim como a construção e ao aprimoramento do bem comum".

Explica Sorrentino et al. (2005) que a educação ambiental se propõe em fomentar a capacidade de educar para a cidadania, construindo um processo de autogestão de sua vida (trabalho) e de seus espaços (ambiente) da sociedade. Contribuindo para formação de uma coletividade que seja responsável pelo mundo em que habita.

Concordam Teixeira et al. (2016) que a principal função da educação ambiental é a formação de 
cidadãos conscientes, responsáveis e preparados para lidar com a realidade local e vivência em sociedade. Na perspectiva socioambiental na comunidade, desenvolver a Educação Ambiental com os moradores não corresponde apenas a utilizar um instrumento para resolução de enigmas ou de gestão ambiental, mas, sobretudo identificar no âmbito social as influências pautadas na base do desenvolvimento pessoal e coletivo entorno da relação entre homem e meio ambiente (FONTES, 2016). Onde compreender esse processo envolve não só a relação entre o ser humano e natureza, mas também a relação entre este e tudo que está em sua volta em termos sociais e culturais (REIGOTA, 2014).

\section{Educação ambiental no contexto das estratégias de saúde da família}

As questões de saúde ao longo das décadas vêm sofrendo diversas transformações que acompanham nossa história, mudanças que se tornaram significativas desde os primórdios do capitalismo até a globalização, atingindo todos os setores de serviços, inclusive o ambiental. Logo, a saúde é determinada como resultante das condições de alimentação, habitação, educação, renda, meio ambiente, trabalho, transporte, emprego, lazer, liberdade, acesso e posse de terra e acesso a serviços de saúde.

Já o equilíbrio entre ter saúde ou doença é uma condição determinada por uma multiplicidade de fatores de origem social, econômica, cultural, ambiental e biológica que afetam ou determinam a saúde das pessoas (CARVALHO, 2012; GEORGE, 2011). Portanto conhecer e discutir as condições pertinente de agravos à saúde e ao ambiente torna-se uma ação essencial para o estabelecimento de medidas de promoção da qualidade de vida do indivíduo, famílias e comunidades (AZEREDO et al., 2007).

A prática da educação ambiental deve colocar as pessoas em contato direto com o mundo e sensibilizá-las para os ecossistemas que as envolvem (REIGOTA, 1994). Para enfrentar os problemas encontrado nas comunidades foi criada em 2006 a portaria 648/MS, aprovando a Política Nacional de Atenção Básica, estabelecendo diretrizes e normas para a organização da Atenção Básica para o Programa Saúde da Família (PSF) e o Programa Agentes Comunitários de Saúde (PACS) estabelecendo que:

As ações na atenção Básica caracterizam-se por um conjunto de ações de saúde, no âmbito individual e coletivo, que abrangem a promoção e a proteção da saúde, a prevenção de agravos, o diagnóstico, o tratamento, a reabilitação e a manutenção da saúde. É desenvolvida por meio do exercício de práticas gerenciais e sanitárias democráticas e participativas, sob a forma de trabalho em equipe, dirigidas a populações de territórios bem delimitados, pelas quais assume a responsabilidade sanitária, considerando a dinamicidade existente no território em que vivem essas populações.

As pessoas envolvidas nesse processo devem ser agentes transformadores, participativos e ativos na elaboração do diagnóstico situacional das comunidades, capazes de contribuir para a elaboração do planejamento para solucionar os problemas, durante o processo de execução contribuir com o monitoramento e avaliação de tais ações (MOISÉS et al., 2010).

As equipes de saúde devem pensar em estratégias e iniciativas que exijam ações comunitárias lançando um olhar integral considerando suas dimensões físicas, socioculturais, biopsicossociais nas quais estão inseridos os indivíduos e suas famílias.

A enfermagem, tem o desafio de habilitar as pessoas para condutas ecologicamente saudáveis por 
meio de ações de promoção de saúde que capacitem o indivíduo e a comunidade a exercerem empoderamento e autonomia e reflexão crítica para uma mudança de comportamento considerando a saúde dentro de um contexto ambiental (BESERRA et al., 2010).

\section{METODOLOGIA}

\section{Caracterização da área e população de estudo}

O município de Cáceres-MT está localizado entre a margem esquerda do rio Paraguai e as rodovias da BR-070, BR-174 e BR-364, na microrregião do Alto Pantanal e na mesorregião do centro sul matogrossense, com uma área territorial de $24.593,123 \mathrm{~km}^{2}$ e perímetro urbano de 8.219 hectares (IBGE, 2018).

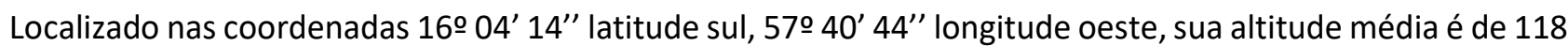
metros ao nível do mar (NEVES et al., 2009).

É uma região de clima tropical semiúmido, com médias de temperaturas máximas anuais com valores entre $30^{\circ} \mathrm{C}$ e $34^{\circ} \mathrm{C}$, mínimas entre $10^{\circ} \mathrm{C}$ e $21^{\circ} \mathrm{C}$. De acordo com o último censo demográfico, o município de Cáceres possui uma população de 93.882 habitantes (IBGE, 2018).
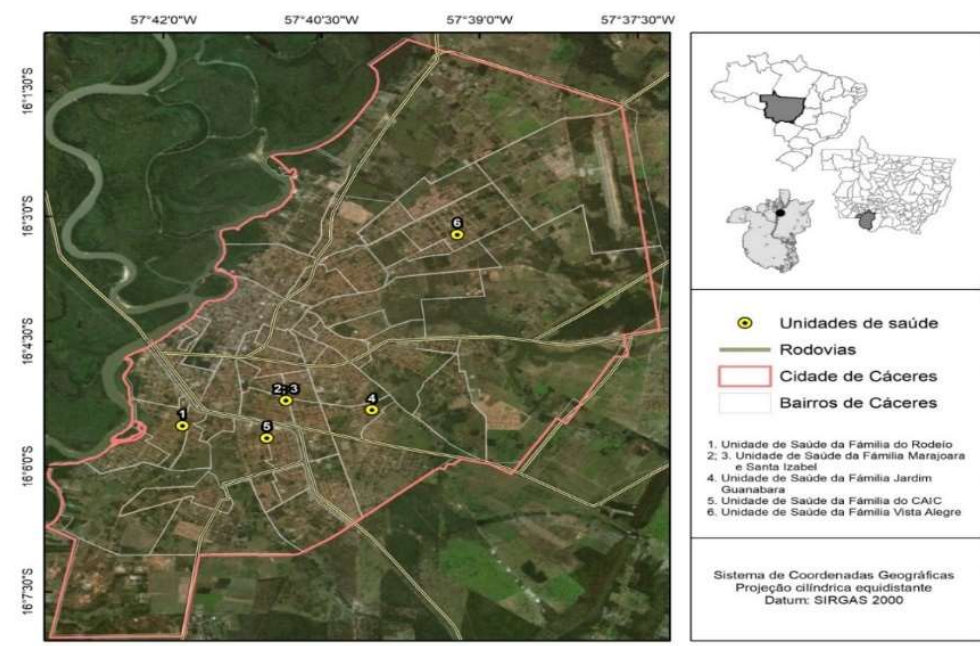

Figura 1: Localização da área de estudo evidenciando as seis unidades de saúde que foram utilizadas para esta pesquisa. Fonte: imagem baseada em Google Earth (2018).

São constatados nessa área a presença de três biomas, sendo elas, o Cerrado, Amazônia e Pantanal (maior predominância). Esses locais, desde o momento em que se tornaram foco do desenvolvimento e da expansão da fronteira agrícola, têm sofrido impactos provenientes da transformação do processo de exploração de riquezas naturais, da abertura de áreas de floresta e cerrado e, a posteriori da modificação do uso e ocupação do solo (LEÃO et al., 2017).

O estudo foi desenvolvido em seis Unidades de saúde, caracterizadas como Estratégias de Saúde da Família, pertencentes a zona urbana do município de Cáceres- MT. Foram selecionadas quatro unidades periféricas e duas unidades mais próximas do centro da cidade (ESF: Rodeio, CAIC, Guanabara, Santa Izabel, Marajoara e Vista alegre) conforme Figura 1. 


\section{Coleta e análise de dados}

As coletas de dados foram realizadas através de um instrumento contendo questões de caráter qualitativo e quantitativos por meio de questionários com roteiro semiestruturado com questões abertas e fechadas (onde os colaboradores ficaram livres para responder com suas próprias palavras, sem se limitar a um rol de alternativas) com o intuito de não levar à indução das respostas.

Na entrevista foi respeitado o direito de escolha do participante em contribuir com a pesquisa, sendo respeitado todas as recomendações aprovadas previamente determinadas pelo Comitê de Ética em Pesquisa da Universidade do Estado de Mato Grosso (CEP/UNEMAT) através do Parecer (2.964.856).

Os dados foram coletados de maneira imparcial, visando não influenciar nas respostas dos entrevistados respeitando a não identificação de cada indivíduo. Os anonimatos dos participantes foram garantidos de acordo com a unidade de cadastro e ordem de participação na pesquisa.

Após a coleta, para a análise dos dados foram realizadas associações pelo Teste Qui quadrado com correção de Bonferroni e uso do teste Exato de Fisher quando identificada associação significativa entre as seis localidades, por meio do programa Bioestat 5.0, considerando um nível de significância de 5\%.

Quanto às análises de dados qualitativos foram preconizadas as técnicas de análise do conteúdo de Laurence Bardin (BARDIN, 2011). O método prevê três fases fundamentais caracterizadas por pré-análise ou reunião do corpus de análise; tratamento dos resultados obtidos com o processo de categorização e posterior interpretação dos dados.

Na primeira etapa foram efetuadas várias leituras (flutuantes) com a finalidade de organizar, ainda que de forma não estruturada, aspectos importantes que permitiram assimilação melhor do material e de algumas reflexões que forneceram pontos para uma possível sistematização dos dados.

Na segunda fase foram selecionadas as categorias que apresentaram relação de interdependência com as questões da pesquisa e relação de dependência com os objetivos do estudo, referencial teórico e as próprias convicções intuitivas do pesquisador sobre o tema. Logo depois da formação das categorias, iniciouse a última etapa do processo, a inferência de conteúdos relativos as mensagens produzidas a partir das informações dos dados (BARDIN, 2011).

Assim, as categorias criadas foram relacionadas com os principais eixos temáticos do estudo: saúde e meio ambiente; Educação ambiental, problemas sanitários e socioambientais e responsabilidade de realizar educação ambiental nas ESFs.

\section{RESULTADOS E DISCUSSÃO}

\section{Perfil sociodemográficos dos usuários de saúde das ESFS de Cáceres-MT}

Na análise do perfil sociodemográfico da população inicialmente é importante destacar que a quantidade de participantes do sexo masculino é superior na ESF Caic em relação Santa Isabel (p=0,004), assim como Caic apresentou uma prevalência de renda mensal superior a 3 salários mínimos significativamente maior que as ESFs Guanabara, Santa Isabel e Vista Alegre $(p=0,02)$. Em relação às variáveis 
faixa etária, escolaridade, estado civil, moradia e número de pessoas nas casas não foram identificadas diferenças entre as localidades participantes $(p>0,05)$. Todos os valores estão detalhados na (Tabela 1).

Tabela 1: Frequência das variáveis sócio demográficas dos 20 participantes de cada ESF Cáceres-MT.

\begin{tabular}{|c|c|c|c|c|c|c|c|}
\hline \multirow[t]{2}{*}{$\begin{array}{l}\text { Variáveis } \\
\text { Sócio demográficas }\end{array}$} & \multicolumn{6}{|l|}{$\begin{array}{l}\text { Local } \\
\%(n)\end{array}$} & \multirow[t]{2}{*}{ Valor de $p^{(D)}$} \\
\hline & Caic & Guanabara & Marajoara & Rodeio & Santa Isabel & Vista Alegre & \\
\hline \multicolumn{7}{|l|}{ Sexo } & \multirow{3}{*}{0,004} \\
\hline Feminino & $50,0(10)$ & $90,0(18)$ & 85,0 (17) & 85,0 (17) & 95,0 (19) & 85,0 (17) & \\
\hline Masculino & $50,0(10)^{A}$ & $10,0(2)^{A B}$ & $15,0(3)^{A B}$ & $15,0(3)^{A B}$ & $5,0(1)^{\mathrm{B}}$ & $15,0(3)^{A B}$ & \\
\hline \multicolumn{8}{|l|}{ Faixa etária } \\
\hline $18 Н 29$ & $50,0(10)$ & $15,0(3)$ & $25,0(5)$ & $15,0(3)$ & $25,0(5)$ & $25,0(5)$ & \multirow[t]{3}{*}{0,38} \\
\hline $30-59$ & $40,0(8)$ & $70,0(14)$ & $65,0(13)$ & $65,0(13)$ & $65,0(13)$ & $70,0(14)$ & \\
\hline $60-79$ & $10,0(2)$ & $15,0(3)$ & $10,0(2)$ & $20,0(4)$ & $10,0(2)$ & $5,0(1)$ & \\
\hline \multicolumn{8}{|l|}{ Escolaridade } \\
\hline Sem instrução & $20,0(4)$ & $30,0(6)$ & $35,0(7)$ & $10,0(2)$ & $30,0(6)$ & $30,0(6)$ & \multirow[t]{3}{*}{0,64} \\
\hline E. Fundamental & $25,0(5)$ & $20,0(4)$ & $10,0(2)$ & $30,0(6)$ & $15,0(3)$ & $10,0(2)$ & \\
\hline E. Médio e Superior & $35,0(7)$ & $50,0(10)$ & $55,0(11)$ & $60,0(12)$ & $55,0(11)$ & $60,0(12)$ & \\
\hline \multicolumn{8}{|l|}{ Estado Civil } \\
\hline Casado & $55,0(11)$ & $70,0(14)$ & $70,0(14)$ & $75,0(15)$ & $45,0(9)$ & $75,0(15)$ & \multirow[t]{3}{*}{0,25} \\
\hline Solteira & $45,0(9)$ & $10,0(2)$ & $20,0(4)$ & $10,0(2)$ & $50,0(10)$ & $10,0(2)$ & \\
\hline Separado/Viúvo(B) & $0,0(0)$ & $20,0(4)$ & $10,0(2)$ & $15,0(3)$ & $5,0(1)$ & $15,0(3)$ & \\
\hline \multicolumn{8}{|l|}{ Rendimento $^{(\mathrm{A})}$} \\
\hline Sem renda(c) & $10,0(2)$ & $5,0(1)$ & $0,0(0)$ & $0,0(0)$ & $0,0(0)$ & $0,0(0)$ & \multirow[t]{3}{*}{0,02} \\
\hline 1 á 2 Salários & $30,0(6)$ & $80,0(16)$ & $70,0(14)$ & $80,0(16)$ & $60,0(12)$ & $85,0(17)$ & \\
\hline$\geq 3$ Salários & $55,0(11)^{A}$ & $15,0(3)^{B}$ & $30,0(6)^{A B}$ & $20,0(4)^{A B}$ & $40,0(8)^{B}$ & $15,0(3)^{B}$ & \\
\hline \multicolumn{8}{|l|}{ Moradia(A) } \\
\hline Alugada & $10,0(2)$ & $0,0(0)$ & $25,0(5)$ & $10,0(2)$ & $10,0(2)$ & $5,0(1)$ & \multirow[t]{2}{*}{0,14} \\
\hline Própria & $90,0(18)$ & $100,0(20)$ & $70,0(14)$ & $90,0(18)$ & $90,0(18)$ & 95,0 (19) & \\
\hline \multicolumn{8}{|l|}{ Pessoas na casa } \\
\hline $1 H 2$ & $15,0(3)$ & $20,0(4)$ & $40,0(8)$ & $15,0(3)$ & $30,0(6)$ & $10,0(2)$ & \multirow[t]{3}{*}{0,14} \\
\hline $3 H_{4}$ & $70,0(14)$ & $55,0(11)$ & $45,0(9)$ & $60,0(12)$ & $50,0(10)$ & $40,0(8)$ & \\
\hline$\geq 5$ & $15,0(3)$ & $25,0(5)$ & $15,0(3)$ & $25,0(5)$ & $20,0(4)$ & $50,0(10)$ & \\
\hline
\end{tabular}

Nota: ${ }^{(\mathrm{A})}$ Um participante não respondeu a questão; ${ }^{(\mathrm{B})}$ Dados da categoria sem renda foram somados a categoria 1 a 2 salários a fim de permitir a análise estatística; ${ }^{(C)}$ Dados da categoria Separado/Viúvo foram somados a categoria Solteiro a fim de permitir a análise estatística; ${ }^{(D)}$ Teste Qui quadrado com correção de Bonferroni. Letras maiúsculas nas linhas apontam a diferença entre os locais pelo pós-teste Exato de Fisher.

\section{Participação dos usuários em ações relacionadas à educação ambiental no contexto das ESF de Cáceres- MT}

Apenas 4,2\% ( $n=5)$ afirmam ter procurado as ESFs para solicitar auxílio sobre algum problema ambiental que prejudicasse a saúde e, devido ao pequeno tamanho amostral de assertivas, não foi possível realizar análise inferencial. Sobre a população ter recebido das equipes das ESFs alguma orientação sobre EA e os riscos à saúde, apesar da maioria $(87,2 \% ; n=101)$ negar este fato, as afirmativas em relação aos participantes usuários da ESF Vista Alegre foram significativamente maiores que na ESF Guanabara $(p=0,009)$. A maioria dos respondentes $(92,5 \% ; n=111)$ negou a participação em algumas ações de saúde e meio ambiente promovida pelas ESFs, sem diferença de proporções entre as ESF ( $p=0,55)$ (Tabela 2$)$.

Tabela 2: Frequência das variáveis relacionada a ações de educação ambiental dos 20 participantes de cada ESF. Cáceres - MT.

\begin{tabular}{|c|c|c|c|c|c|c|c|}
\hline \multirow[t]{2}{*}{ Ações de Educação ambiental } & \multicolumn{6}{|l|}{$\begin{array}{l}\text { Local } \\
\%(n)\end{array}$} & \multirow[t]{2}{*}{$\begin{array}{l}\text { Valor de } \\
p^{(A)}\end{array}$} \\
\hline & Caic & Guanabara & Marajoara & Rodeio & $\begin{array}{l}\text { Santa } \\
\text { Isabel }\end{array}$ & $\begin{array}{l}\text { Vista } \\
\text { Alegre }\end{array}$ & \\
\hline $\begin{array}{l}\text { Solicitou auxílio sobre problema ambiental } \\
\text { que prejudicasse a saúde }\end{array}$ & $\begin{array}{l}10.0 \\
(2)\end{array}$ & $5.0(1)$ & $5.0(1)$ & $0.0(0)$ & $0.0(0)$ & $5.0(1)$ & -- \\
\hline Recebeu da equipe da ESF orientações sobre & 25.0 & $0.0(0)^{\mathrm{b}}$ & $10.0(2)^{\mathrm{ab}}$ & 10.0 & 10.0 & $40.0(8)^{a}$ & 0,009 \\
\hline
\end{tabular}




\begin{tabular}{|c|c|c|c|c|c|c|c|}
\hline EA e os riscos à saúde & $(5)^{a b}$ & & & $(2)^{a b}$ & $(2)^{\mathrm{ab}}$ & & \\
\hline $\begin{array}{l}\text { Participou de ação de saúde e meio ambiente } \\
\text { promovida pela ESF }\end{array}$ & $\begin{array}{l}5.0 \\
(1)\end{array}$ & $10.0(2)$ & $0.0(0)$ & $\begin{array}{l}15.0 \\
(3)\end{array}$ & $5.0(1)$ & $10.0(2)$ & 0,55 \\
\hline
\end{tabular}

Nota: ${ }^{(A)}$ Teste qui quadrado com correção de Bonferroni. Letras minúsculas nas linhas apontam a diferença entre os locais pelo pós-teste Exato de Fisher. (--) Não foi realizada análise estatística inferencial devido ao pequeno tamanho amostral por localidade.

De acordo com os achados foi evidenciado que a maioria dos participantes não procuram as unidades para solicitar ou relatar algum tipo de problema ou risco ambiental nas comunidades. Sendo possível identificar que grande parcela das equipes das ESFs também não preconiza em suas práticas de saúde a realização de ações e orientações que abarque tal temática.

Revelando assim a falta de interesse tanto dos usuários como dos profissionais de saúde em discutir ações com ênfase em saúde e meio ambiente e educação ambiental, limitando a criação de ambientes favoráveis a saúde. Concordam lanni et al. (2006) que a questão ambiental é pouco discutida pelas equipes das ESFs, deficiência esta que possui bases na própria concepção de ambiente que a Estratégia de Saúde tem e que está expressa em suas normas e diretrizes.

De acordo com Brasil (2001) as atividades que englobam a saúde e o ambiente estão expressa entre as principais atribuições das equipes de saúde envolvendo desde o conhecer a realidade das famílias e situações de risco; identificação de diagnóstico local; elaboração de um planejamento e intervenções para resolução da situação real; execução de ações de vigilância epidemiológica, ambiental e sanitária; entre outras ações para a melhoria da qualidade de vida e do meio ambiente.

Assim entender a questão ambiental em sua totalidade e complexidade é um dos pressupostos na busca de práticas de intervenção para além das curativas e preventivas aproximando cada vez mais dos preceitos da promoção da Saúde, ou seja, o desenvolvimento de práticas menos individuais e mais coletivas, menos assistencialistas e mais participativas, o que auxiliará os indivíduos a assumir o controle sobre sua saúde e melhores condições de qualidade de vida (MENDONÇA et al., 2012).

\section{Percepção dos usuários sobre saúde e meio ambiente: educação ambiental nas ESFS de Cáceres-MT}

Quanto à percepção dos usuários sobre saúde e meio ambiente e educação ambiental nas ESFs de Cáceres, a categoria "Conservação e preservação ambiental" foi a mais prevalente 21,7\% ( $n=26)$ e a categoria "Relação de ambiente e saúde" foi a menos prevalente 2,5\%, $(n=3)$. Totalizaram $28,3 \%(n=34)$ os usuários que declararam não saber ou não responderam este questionamento (Tabela 3).

Tabela 3: Distribuição das categorias relacionadas à percepção dos usuários sobre saúde e meio ambiente: educação ambiental nas ESFs de Cáceres- MT.

\begin{tabular}{|c|c|c|c|c|c|c|c|}
\hline \multirow[t]{2}{*}{$\begin{array}{l}\text { Categorias de percepção ambiental dos } \\
\text { usuários }\end{array}$} & \multicolumn{6}{|l|}{$\begin{array}{l}\text { Local } \\
\%(n)\end{array}$} & \multirow[t]{2}{*}{$\begin{array}{l}\text { Total } \\
(120)\end{array}$} \\
\hline & Caic & Guanabara & Marajoara & Rodeio & $\begin{array}{l}\text { Santa } \\
\text { Isabel }\end{array}$ & $\begin{array}{l}\text { Vista } \\
\text { Alegre }\end{array}$ & \\
\hline Educação ambiental & $0,0(0)$ & $20,0(4)$ & $0,0(0)$ & $15,0(3)$ & $10,0(2)$ & $10,0(2)$ & $9,2(11)$ \\
\hline Conservação / preservação ambiental & $35,0(7)$ & $25,0(5)$ & $10,0(2)$ & $25,0(5)$ & $15,0(3)$ & $20,0(4)$ & $21,7(26)$ \\
\hline Degradação ambiental & $10,0(2)$ & $10,0(2)$ & $15,0(3)$ & $15,0(3)$ & $10,0(2)$ & $15,0(3)$ & $12,5(15)$ \\
\hline Relação de ambiente e saúde & $5,0(1)$ & $10,0(2)$ & $0,0(0)$ & $0,0(0)$ & $0,0(0)$ & $0,0(0)$ & $2,5(3)$ \\
\hline Saneamento básico & $0,0(0)$ & $25,0(5)$ & $35,0(7)$ & $15,0(3)$ & $20,0(4)$ & $5,0(1)$ & $16,7(20)$ \\
\hline Importância/ Integrados/ Interligados/ & $5,0(1)$ & $0,0(0)$ & $5,0(1)$ & $0,0(0)$ & $30,0(6)$ & $15,0(3)$ & $9,2(11)$ \\
\hline
\end{tabular}


Relacionado

Não sabe / não respondeu/ Não há 45,0(9) $10,0(2) \quad 35,0(7) \quad 30,0(6) \quad 15,0(3) \quad 35,0(7)$ existência

$\mathrm{Na}$ tabela 3, ficou claro que parte dos entrevistados denotam pouca ou nenhuma percepção sobre as categorias ligadas aos aspectos da saúde e meio ambiente: educação ambiental nas ESFs. Foi identificado que o ato de preservação e conservação do ambiente quando analisadas em conjunto foram as mais relevantes nos achados da pesquisa, a percepção sobre a relação de saúde e meio ambiente quase não foi mencionado pelos usuários.

Estudos realizados por Silva (2015) considera a importância da sociedade se conscientizar quanto a preservação do meio ambiente visando à sustentabilidade para que a população presente e as futuras usufruam dos bens naturais e da qualidade de vida.

Contudo, para que a sociedade tenha entendimento nessa fundamentação faz-se necessário que as instituições educacionais tenham a preservação e a conservação ambiental como políticas institucionais diárias, e que esses temas sejam colocados na pauta de discussões do processo de educação permanente dentro do contexto do ensino (BARBOZA et al., 2016).

Desde a Conferência das Nações Unidas de Estocolmo em 1972, consta na declaração do meio ambiente um chamamento aos governos, povos e às gerações futuras, sobre a importância de cuidar da natureza até pela própria sobrevivência (BRASIL, 1993). De acordo com essa proposta caberia ao sistema público efetivar ações para o desenvolvimento da EA, contudo ainda essa questão em localidades menores nos casos de Cáceres, ainda está muito aquém do desejável, visto que é notável a deficiência de projetos públicos que estimule a preservação e conservação ambiental no município.

\section{Percepção dos usuários de saúde sobre a responsabilidade de realizar a educação ambiental no município de Cáceres-MT}

Dentre os 120 usuários respondentes da pesquisa $73,3 \%(n=88)$ consideraram que a responsabilidade de realizar a educação ambiental no município de Cáceres é do setor público, citando a prefeitura, as ESFs, a vigilância e outros órgãos públicos. Esta percepção foi significativamente maior entre os participantes da ESF Caic em relação à ESF Rodeio $(p=0,006)$. Consideraram em segundo plano que a responsabilidade da EA é da Comunidade e da escola $42,5 \%(n=51)$ e apenas $6,7 \%(n=8)$ não sabiam ou não responderam. Não havendo diferença de percepção destas categorias entre as comunidades $(p>0,05)$ (Tabela 4).

Tabela 4: Frequência das respostas de acordo com percepção dos usuários sobre a responsabilidade de realizar a educação ambiental no município de Cáceres-MT.

\begin{tabular}{|c|c|c|c|c|c|c|c|}
\hline \multirow[t]{2}{*}{$\begin{array}{l}\text { Responsável } \\
\text { ambiental }\end{array}$} & \multicolumn{6}{|l|}{$\begin{array}{l}\text { Local } \\
\%(n)\end{array}$} & \multirow[t]{2}{*}{$\begin{array}{l}\text { Valor de } \\
p^{(a)}\end{array}$} \\
\hline & Caic & Guanabara & Marajoara & Rodeio & $\begin{array}{l}\text { Santa } \\
\text { Isabel }\end{array}$ & $\begin{array}{l}\text { Vista } \\
\text { Alegre }\end{array}$ & \\
\hline $\begin{array}{l}\text { Prefeitura/ ESF/ Vigilância /Órgãos } \\
\text { públicos }\end{array}$ & $\begin{array}{l}95,0 \\
(19)^{\mathrm{a}}\end{array}$ & $90,0(18)^{\mathrm{ab}}$ & $80,0(16)^{\mathrm{ab}}$ & $\begin{array}{l}50,0 \\
(10)^{\mathrm{b}}\end{array}$ & $65,0(13)^{a b}$ & $60,0(12)^{a b}$ & 0,006 \\
\hline Comunidade/ Escola & $40,0(8)$ & $25,0(5)$ & $50,0(10)$ & $55,0(11)$ & $45,0(9)$ & $40,0(8)$ & 0,49 \\
\hline Não respondeu/ Não sabe & $10,0(2)$ & $5,0(1)$ & $5,0(1)$ & $5,0(1)$ & $10,0(2)$ & $5,0(1)$ & 0,96 \\
\hline
\end{tabular}

Nota: Foram identificadas de mais de uma resposta por usuário. As respostas 'Não respondeu/ Não sabe foram desconsideradas na análise estatística, pelo pequeno número de observações. 
Foi evidenciado na tabela 05 , no quesito de quem incorre a responsabilidade de realizar a EA nas unidades no município de Cáceres-MT, é da prefeitura e dos órgãos públicos conforme os discursos dos usuários, sendo identificado nesse contexto que a população tem parcialmente ciência dessa questão. Posto que foram apontado menor atribuição para as comunidades e escolas, fato que nos mostra que o desenvolvimento da educação ambiental não tem sido uma atividade amplamente efetiva e desenvolvida em âmbito escolar, conforme o propósito das conferências e preceito constitucional, já que pouco fora mencionado pelos participantes.

No Brasil, a efetivação de ações governamentais relativas ao meio ambiente ocorreram a partir da promulgação da Constituição Federal de 1988, artigo 225 que expressa o direito de posse de um meio ambiente ecologicamente equilibrado deixando claro que cabe ao poder público realizar a EA nas comunidades, contudo a responsabilidade de preservá-la é atribuição da coletividade.

Conforme a Política nacional de Educação ambiental (PNEA), lei 9.795/99 no Art. 9o da Constituição Federal, a EA deve estar presente e ser desenvolvida no âmbito dos currículos das instituições de ensino público e privado, englobando: I-Educação básica: a. Educação infantil; b. Ensino fundamental e c. Ensino médio; II- Educação superior; III- Educação especial; IV -Educação profissional; V- Educação para jovens e adultos; VI- Educação especial e indígena (FIGUEIRÓ, 2015).

Segundo essa legislação a EA deve ser desenvolvida em todos os segmentos e níveis da educação como uma prática educativa integrada, contínua e permanente devendo permear todas as relações e atividades escolares de maneira interdisciplinar refletindo em questões atuais e futuras que envolvem o contexto ambiental.

Nesse sentido observou se a necessidade de construir uma proposta de ensino capaz de educar e formar cidadãos conscientes de suas responsabilidades individuais e coletivas em relação a preservação e conservação do ambiente global.

Relatos dos usuários sobre saúde e meio ambiente: educação ambiental no contexto das ESFS Cáceres-MT Preservação ambiental

\footnotetext{
"Um ambiente saudável em condições higiênicas é o único meio do ser humano de ter uma vida saudável, por isso temos que preservar." (ESF CAIC)

"Para viver bem a gente deve cuidar do meio ambiente". (ESF Guanabara)

"Para ter saúde nós precisamos de um ambiente saudável"; "Se estiver poluído é prejudicial à saúde"; "Não sei informar". (ESF Marajoara)

"Reciclagem dos lixos, plantar plantas e não fazer queimadas"; "Sem meio ambiente conservado, sem árvores, não teremos saúde"; "Não sei informar". (ESF Rodeio)

"Preservar as árvores para respirar melhor, quanto mais queimadas mais poluição ambiental"; "Não sei informar". (ESF Santa Isabel)

"Falta um ambiente com mais árvores e mais preservação ambiental"; "Devemos preservar a água, os animais e as plantas, a natureza, os peixes e os rios etc."; "Sem o meio ambiente não temos árvores nem existência de animais. (ESF Vista alegre)
} 


\section{Conservação ambiental}

“Para ter saúde o meio ambiente deve estar conservado". (ESF CAIC)

"Não citaram" e "Não sei informar". (ESF Guanabara); (ESF marajoara); (ESF Rodeio); (ESF Santa Isabel); (ESF Vista Alegre)

\section{Degradação ambiental}

\section{Educação ambiental}

"Poluição e as queimada é prejudicial à saúde"; "A contaminação dos rios por resíduos sólidos é ruim pra todos do meio ambiente". (ESF CAIC)

"O meio ambiente poluído e água parada é prejudicial à saúde" (ESF Guanabara)

"Saúde e o meio ambiente está um caos"; "O ideal para a saúde seria não ter desmatamento e nem queimadas"; “Não sei informar”. (ESF Marajoara)

"A poluição ambiental é prejudicial à saúde"; "Quando jogamos os lixos nos córregos, nós prejudicamos a nossa própria vida e as dos peixes" "Quando o ambiente está poluído também adoecemos"; "Não sei informar". (ESF Rodeio)

"Quando se tem um ambiente poluído não se tem saúde". "As pessoas poluem o ambiente com muitos resíduos sólidos jogados nos terrenos baldios". (Santa Isabel)

"O meio ambiente e a saúde estão ligados"; "Quando o ambiente está poluído a pessoa também se polui, o ambiente é igual sua casa representa tudo para a saúde, o que pode gerar as doenças". (ESF Vista Alegre).

\section{“Não citaram". (ESF CAIC)}

"Educação ambiental deve ser feita pelos moradores". "Conscientização de todos, e divulgação de práticas ambientais"; "tem muita poluição que prejudica a saúde"; "É preciso o meio ambiente ser limpo, os lixos e esgoto ser tratados"; "Todos nós devemos fazer parte da educação ambiental mas as pessoas não tem educação e jogam os lixos na rua". (ESF Guanabara)

"Educar é cuidar o ambiente para ter saúde". (ESF Marajoara)

"A educação no ambiente é uma forma de preservar a natureza contribuindo para a saúde"; “As pessoas não fazem a educação ambiental”. (ESF Rodeio)

"A gente tem que cuidar do ambiente para gerar uma boa saúde, é conscientizar". "Em meu ver a educação é através de gestos de consciência"; "Educação ambiental se dá na prevenção, onde há no ensino da escola e em casa, sem isso morremos aos poucos". (ESF Santa isabel)

"A educação ambiental envolve a orientação da população quanto aos riscos para adoecer. É importante as pessoas serem educadas e não jogar lixo na rua". (ESF Vista Alegre)

\section{Saneamento Básico}

"Coleta de lixo adequada"; "o ambiente limpo, sem poluição para ter saúde". (ESF Caic)

"Se tiver tudo limpo e perfeito, nada que prejudique a saúde"; Os gestores da saúde dar mais atenção para a saúde". (ESF Guanabara)

"É um conjunto de medidas em prol da coletividade: água, saneamento básico, destino do lixo". "Para ter saúde precisa ter água limpa"; "Saneamento está relacionado ao abastecimento de água, ao esgoto sanitário, poluição e medidas de higiene". (ESF Marajoara)

"Manter o local sempre limpo, não jogar os lixos nas ruas"; "O Meio ambiente deve ser limpo e saudável para ter saúde". (ESF Rodeio) 
"Envolve o cuidado com os quintais e com a limpeza, não jogar lixo nas ruas"; "Um ambiente limpo é essencial para o bem-estar e saúde das pessoas"; "Higiene nos bairros e nas casas é fundamental para a saúde de todos". (ESF Santa Isabel)

“O ambiente livre de riscos, fumaça e lixo é muito importante para saúde". (ESF Vista Alegre)

\section{Relação de ambiente com a saúde}

"São grandezas que estão conectadas, se não cuidar do ambiente a saúde do ser humano poderá ficar comprometida";

“O meio ambiente é o único meio do ser humano ter uma vida saudável, por isso temos que preservar". (ESF CAIC)

"Os dois estão integrados, um depende do outro". (ESF Guanabara)

“O nosso ambiente é importante para ter saúde, ambiente limpo para uma boa saúde". (ESF Marajoara)

"O meio ambiente está relacionado com as condições de saúde, a educação deve ser dos moradores"; "A gente tem que cuidar do meio ambiente para ter saúde". (ESF Rodeio)

"A saúde deve estar interligada com o meio ambiente para a melhora da qualidade de vida das pessoas"; "O ambiente interfere na saúde, ambos estão diretamente relacionados". (ESF Santa Isabel)

"Quando relacionamos saúde e meio ambiente, estamos referindo a um casamento". (ESF Vista Alegre)

Os relatos dos participantes nos revelaram um quadro preocupante, ficando perceptível que a maioria não conseguiu construir um conceito organizado e completo sobre o assunto. Esboçaram fragmentos que se aproximavam da construção do conceito, sendo considerável a quantidade de entrevistados que responderam que não sabiam informar ou que não entendiam nada a respeito, confirmando assim a falta de conhecimento prévio sobre o assunto ou aptidão para responder sobre seu espaço de convivência na comunidade, ficando evidente que possuíam percepção sobre a importância de ter um ambiente limpo e saudável expondo a necessidade de preservar e conservar o meio ambiente para obtenção de saúde, entretanto não se colocavam como responsável em realizar ou participar de alguma ação ambiental.

Constata-se que não percebiam o ambiente como essencial para a sua vivência, ou seja, a necessidade de apropriar e empoderar-se do meio ambiente; como consequência não se responsabilizavam pelos espaços em sua volta.

Quanto a expressão 'educação ambiental', foi mencionada vagamente por uma minoria denotando pouco conhecimento sobre o assunto, nesse contexto não conseguiram construir um conceito com elementos integrados sobre o assunto.

Segundo as conferências internacionais a EA, constitui um direito assegurado ao cidadão conforme disposto nos artigos 20 e 30 da legislação brasileira. Devendo ser desenvolvida em todos os níveis de ensino e atingir todas as faixas etárias, menciona Brasil (2009; 1999):

Art. 2º educação ambiental é um componente essencial e permanente da educação nacional, devendo estar presente, de forma articulada, em todos os níveis e modalidades do processo educativo, em caráter formal e não formal. Art. 3 Como parte do processo educativo mais amplo, todos têm direito à educação ambiental, incumbindo: I - ao Poder Público, nos termos dos arts. 205 e 225 da Constituição Federal, definir políticas públicas que incorporem a dimensão ambiental, promover a educação ambiental em todos os níveis 
de ensino e o engajamento da sociedade na conservação, recuperação e melhoria do meio ambiente; II - às instituições públicos educativas, promover a educação ambiental de maneira integrada aos programas educacionais que desenvolvem; [...]. VI -à sociedade como um todo, manter atenção permanente à formação de valores, atitudes e habilidades que propiciem a atuação individual e coletiva voltada para a prevenção, a identificação e a solução de problemas ambientais.

Cabendo a cada país, estados e municípios, implementar a proposta de EA por meio dos órgãos públicos educacionais e de controle ambiental. De acordo com Reigota (1994) a prática de educação ambiental deve colocar as pessoas em contato direto com o mundo e sensibilizá-las para os ecossistemas que as envolvem.

Contudo para que ocorra a efetivação da proposta da educação ambiental nas ESFs faz se necessário conhecer, discutir e abordar a complexidade das relações entre meio ambiente e sociedade destacando os cuidados com a prevenção de doenças, tornando-se efetivamente uma estratégia de prevenção da Atenção Primária em saúde.

\section{CONSCLUSÕES}

O estudo de percepção dos usuários em torno da saúde e do ambiente: educação ambiental em algumas ESFs de Cáceres-MT, possibilitaram visualizar aspectos que interferem na dinâmica da sustentabilidade em diversas dimensões: ambiental, social, econômica, política e cultural. De acordo com as análises das percepções a maioria dos entrevistados percebem os aspectos que relacionam a saúde com ambiente onde vive e identificam fatores de riscos sanitários e socioambientais que degradam a vida em comunidade. Mas não relatam ser atuantes em ações ou eventos que favoreçam os cuidados e a proteção ambiental. A educação ambiental nas ESFs foi vagamente mencionada, confirmando que as pessoas desconhecem ou optaram em não responder sobre o tema. As ações realizadas nas unidades são pontuais com ênfase nos aspectos das doenças, sendo comum a abordagem sobre a dengue e zika. Evidenciou se que a maioria não procura as unidades para relatar nenhum tipo de risco ambiental nas comunidades denotando a falta de interesse tanto dos profissionais quanto dos usuários em discutir propostas que envolvam as questões de ambiente e saúde, limitando as condições que sejam favoráveis a vida em comunidade.

\section{REFERÊNCIAS}

AZEREDO, C. M.; COTTA, R. M. M.; SCHOTT, M.; MAIA, T. M.; MARQUES, E. S.. Avaliação das condições de habitação e saneamento: a importância da visita domiciliar no contexto do Programa de Saúde da Família. Ciência e saúde coletiva, Rio de Janeiro, v.12, n.3, 2007. DOI:

http://dx.doi.org/10.1590/S1413-81232007000300025

BARBOZA, L. A. S.; BRASIL, D. S. B.; CONCEIÇÃO, G. S.. Percepção ambiental dos alunos do 6ㅇ e 9ㅇ anos de uma escola pública municipal de Redenção, Estado de Pará, Brasil. Rev. Pan-Amaz. Saúde, v.7, n.4, p.11-20, 2016.

BARDIN, L.. Cartilha do comitê de ética em pesquisa. In: Resolução do Conselho Nacional de Saúde-(CNS)-466/2012. Análise de conteúdo, São Paulo, 2011. p.2-29.
BESERRA, E. P.; ALVES, M. D. S.; PINHEIRO, P. N. C.; VIEIRA, N. F. C.. Educação ambiental e enfermagem: uma integração necessária. Rev. Bras. de Enferm., Brasília, v.63, n.5, p.84852,2010

BRASIL. Constituição da República Federativa do Brasil. Brasília: Senado Federal, 1988.

BRASIL. Lei $n$ 0 9.795/1999 de 27 de abril de 1999. Dispõe sobre a educação ambiental, institui a Política Nacional de Educação Ambiental e dá outras providências. Brasília: DOU, 1999.

BRASIL. Ministério da Educação. Conselho Nacional de Educação. Resolução № 2, de 15 de junho de 2012. Estabelece as Diretrizes Curriculares Nacionais para a 
Educação Ambiental. Brasília: MEC, 2012.

BRASIL. Ministério da Educação. Programa de educação ambiental-ProNEA: documento básico. Ministério do Meio Ambiente, Diretoria de Educação Ambiental. Ministério da Educação, Coordenação Geral da Educação ambiental. 2 ed. Brasília, 2004

BRASIL. Ministério da Saúde (BR). Secretaria de Políticas da Saúde. Guia prático do programa saúde da família. Brasília: Ministério da Saúde, 2001.

BRASIL. Ministério da Saúde. Uma Estratégia para a Reorganização do Modelo Assistencial. Brasília: MS, 2007.

BRASIL. Ministério das Relações Exteriores. Fundação Alexandre Gusmão. Conferência das Nações Unidas sobre Meio Ambiente e Desenvolvimento: Relatório da Delegação Brasileira. Brasília: FUNAG, 1993.

BRASIL. Ministério do Meio Ambiente. Lei 9.795/99. Política Nacional de Educação Ambiental. Brasília: MMA, 2009.

BROMBERGER, S. M. T.. A Estratégia Saúde da Família numa Perspectiva Ambiental para a Promoção da Saúde. Boletim de Saúde UFRG, Porto Alegre, v.36, n.2, 2003.

BURSZTYN, M. A.; BURSZTYN, M.. Fundamentos de política e gestão ambiental: caminhos para a sustentabilidade. Rio de Janeiro: Garamond, 2012.

CARVALHO, A. I.. Determinantes sociais, econômicos e ambientais da saúde. In: FIOCRUZ. Fundação Oswaldo Cruz. A saúde no Brasil em 2030: diretrizes para a prospecção estratégica do sistema de saúde brasileiro. Rio de Janeiro: FIOCRUZ, 2012.

CARVALHO, L. M.; TOMAZELLO, M. G. C.; OLIVEIRA, H. T.. Pesquisa em educação ambiental: panorama da produção brasileira e alguns de seus dilemas. Cadernos CEDES, Campinas, v.29, n.77, 2009.

DIAS, G. F.. Educação Ambiental: princípios e práticas. São Paulo: Gaia, 2000.

DÍAZ, A. P.. La educación ambiental como proyecto. 2 ed. Barcelona: ICE, 1995.

FIGUEIRÓ, P. S.. Educação para a Sustentabilidade em cursos de graduação em Administração: proposta de uma estrutura analítica. Tese (Doutorado) - Universidade Federal do Rio Grande do Sul, Porto Alegre, 2015.

FIORINO, D. J.. Sustainability as a conceptual focus for Public Administration. Public Administration Review, v.70, n.1, p.78-88, 2010.

FONTES, A. R.. Análise socioambiental da microbacia do rio Caiçá no perímetro urbano de Simão Dias-SE. Dissertação (Mestrado em Desenvolvimento e Meio Ambiente) Universidade Federal de Sergipe, São Cristóvão, 2016.

FONTES, A. R.; BASTOS, R. P. N.; SANTOS, M. B. S.. condições socioambientais de saneamento básico no conjunto Santa Terezinha, bairro Novo Horizonte, Lagarto (SE): desafios frente à educação ambiental Rev. Bea, São Paulo, v.12, n.1, p.97-114, 2017.
IANNI, A. M. Z; QUITÉRIO, L. A. D. A.. questão ambiental urbana no Programa de Saúde da Família: avaliação da estratégia ambiental numa política pública de saúde. Rev. Ambiente \& Sociedade, Campinas, v.9, n.1, p.180-96, 2006

IBGE. Instituto Brasileiro de Geografia e Estatística. Censo Demográfico 2018. Brasília: IBGE, 2018.

LE PRESTRE, P.. Eco política Internacional. São Paulo: Senac, 2000.

LEÃO, D. S.; CASTRILON, S. K. I.; BAMPI, A. C.; QUEIROZ; H. M.; PUHI, J. I.. Problemas socioambientais no pantanal matogrossense, assentamento Laranjeiras, Cáceres, MT. Ciência Geográfica, Bauru, v.21, n.1, 2017

LIMA, G. F. C.. A institucionalização das políticas e da gestão ambiental no Brasil: avanços, obstáculos e contradições. Desenvolvimento e Meio Ambiente, n.23, p.121-132, 2011.

MORADILIO, E. F.; OKI, M. C. M.. Educação ambiental na universidade: construindo possibilidades. Quim Nova, v.27, n.2, p.332-6, 2004.

MENDONÇA, R. C.; GIATTI, L. L.; TOLEDO, R. F. A.. Temática Ambiental em Representações e Práticas de Profissionais de Saúde da Família no Município de Manaus - AM/Brasil. Saúde Soc. São Paulo, v.21, n.3, p.776-787, 2012.

MOISÉS, M.; KLIGERMAN, D. C.; COHEN, S. C.; MONTEIRO, S. C. F.. A política federal de saneamento básico e as iniciativas de participação, mobilização, controle social, educação em saúde e ambiental nos programas governamentais de saneamento. Ciência e saúde coletiva, Rio de Janeiro, v.15, n.5, 2010

MORAES, A. S. P; LIMA, J. H. M.; ABREU, B. S.; ABREU, I. G.; ABREU, P. S.. Educação ambiental como Estratégia na Atenção Primária em Saúde. Polêmica, v.13, n.3, 2014.

NEVES, R. J.; CRUZ, C. B. M.. Elaboração e implementação de atlas municipais: uma proposta para o ensino de Geografia de localidade - Cáceres, MT - Brasil. In: SIMPÓSIO DE GEOTECNOLOGIAS NO PANTANAL, 2. Anais. Corumbá: Embrapa Informática Agropecuária/INPE, 2009. p.10491058.

PERES, R. R.; CAMPONOGARA, S.; COSTA, V. Z.; TERRA, M. G.; NIETSCHE, E. A.. Educação ambiental para docentes enfermeiros: percepção e relação com a formação do enfermeiro. Rev. Gaúcha Enferm., v.36, p.85-93, 2015.

RAMOS, E. C.. Educação ambiental: origem e Perspectivas. Educar, Curitiba, n.18, p.201-218, 2001.

REIGOTA, M.. O que é educação ambiental. Brasiliense: São Paulo, 1994.

REIGOTA, M.. O que é Educação Ambiental. 2 ed. São Paulo: Brasiliense, 2014.

SILVA, L. U.. Disposição final de resíduos sólidos urbanos e a responsabilidade dos geradores e do poder público Monografia (Especialização em Gestão Ambiental em Municípios) - Universidade Tecnológica Federal do Paraná, Medianeira, 2015. 
SORRENTINO, M.; TRAJBER, R.; MENDONÇA, P.; JUNIOR

FERRARO, L. A. Educação ambiental como política pública. Educação e Pesquisa, v.31, n.2, p.285-299, 2005.

TEIXEIRA, L. I. L.; SILVA FILHO, J. C. L.; MEIRELES, F. R. S.. Consciência e Atitude Ambiental em Estudantes de Instituições de Ensino Técnico e Tecnológico. Rev. Eletrônica em Gestão, Educação e Tecnologia Ambiental Santa Maria, v.20, n.1, p.334-350, 2016.
UNESCO. Conferência de Tbilisi - 1977. Recomendação 1. In: SÃO PAULO. Secretaria do Meio ambiente. Educação ambiental e desenvolvimento: documentos oficiais. São Paulo, 1994. p.31.

WU, X.; RAMESH, M.; HOWLLET, M.; FRITZEN, S.. Guia de políticas públicas: gerenciando processos. Brasília: ENAP, 2014.

A CBPC - Companhia Brasileira de Produção Científica (CNPJ: 11.221.422/0001-03) detém os direitos materiais desta publicação. Os direitos referem-se à publicação do trabalho em qualquer parte do mundo, incluindo os direitos às renovações, expansões e disseminações da contribuição, bem como outros direitos subsidiários. Todos os trabalhos publicados eletronicamente poderão posteriormente ser publicados em coletâneas impressas sob coordenação da Sustenere Publishing, da Companhia Brasileira de Produção Científica e seus parceiros autorizados. Os (as) autores (as) preservam os direitos autorais, mas não têm permissão para a publicação da contribuição em outro meio, impresso ou digital, em português ou em tradução. 